\title{
Testing twin deficits hypothesis using VARs and Variance decomposition
}

\begin{abstract}
This paper examines the twin deficits hypothesis in the ASEAN countries. The major findings of this paper are the following. (1) Long run relationships are detected between budget and current account deficits. (2) The Keynesian view fits well for Thailand since the causality runs from budget deficit to current account deficit. For Indonesia, the causality runs in an opposite direction while the empirical results indicate that a bidirectional pattern of causality exists for Malaysia and the Philippines. (3) We also found support for an indirect causal relationship that runs from budget deficit to higher interest rates, and higher interest rates leading to the appreciation of the exchange rate, which in turn leads with the widening of the current account deficit. The results of the variance decompositions and impulse response functions suggest that the consequences of large budget and current account deficits become noticeable only over the long run.
\end{abstract}

Keyword: Twin deficits, cointegration, variance decomposition 